\title{
ANALISIS KONSEP TRI HITA KARANA PADA DAYA TARIK WARISAN BUDAYA: STUDI KASUS PURI AGUNG KARANGASEM, BALI
}

\author{
Kadek Wiweka \\ Double Degree Indonesia Prancis (DDIP) \\ Program Magister Kajian Pariwisata Universitas Udayana \\ dan Université Angers, France \\ Email: deka_deka88@yahoo.com
}

\begin{abstract}
This article discusses how local wisdom, namely Tri Hita Karana (three cause of harmony and prosperity), can support sustainable tourism, such as in cultural tourism attraction of Puri Agung Karangasem, Bali. This Puri (palace) has a great potency to become a cultural tourism product an can be developed with considerable community involvement. The Puri has selected Tri Hita Karana concept as the basis of tourist attraction's management by giving specific attention to the three elements of Tri Hita Karana including parahyangan (spiritual/culture), pawongan (community), and palemahan (environment). Data for this study was collected through interview method to find description of the implementation of the concept of Tri Hita Karana in managing Puri Agung Karangasem as tourist attraction. Hereinafter, informants involved are the Puri's management, local community and experts associated with Tri Hita Karana or sustainable tourism. These data were combined with secondary data such as reports or literature related with the object of research and presented in the form of description. This study concludes that the implementation of Tri Hita Karana in Puri Agung Karangasem have positive impact on all aspects involved in tourism activities, such as community, local culture and environment. These aspects are also considered as an important factor and attraction for both domestic and international tourists.
\end{abstract}

Keywords: Implementation, Cultural Heritage Attraction, Tri Hita Karana, Sustainable tourism. 


\section{Pendahuluan}

Tndonesia merupakan salah satunegara dikawasan Asia Tenggara

Iyang banyak memiliki pusaka budaya (heritage) dari masa lalu baik yang bersifat tangible, intangible maupun abstrak (Adrika, 2007:X), di mana salah satunya adalah Bali. Picard (2006:21) mencatat bahwa pulau Bali tersohor di dunia karena keindahan pemandangannya dan lebih lagi karena kekayaan tradisi kesenian dan religinya. Selain itu juga ditambahkan, bahwa perkembangan pariwisata atas dasar budaya Bali tidak terlepas dari peran kolonial Belanda yang menganggap Bali sebagai "museum hidup" (living monument) dari kebudayaan Hindu-Jawa, yaitu penampungan warisan Hindu Majapahit yang terdesak dari Jawa saat datangnya Islam (Pichard, 2006:26; Ardika, 2007:30).

Adapun bukti fisik tentang keberadaan kerajaan-kerajaan Bali yaitu istana raja yang dalam bahasa Bali dinamakan puri agung. Pada dasarnya setiap kerajaan di Bali, setelah runtuhnya Majapahit pada abad ke-14, mempunyai puri persemayaman raja (Munandar, 2005:X). Puri-puri di Bali dibangun dengan mengikuti berbagai aturan tertentu, antara lain kompleks puri yang terbagi dalam beberapa pelebahan, di mana pengertian pelebahan adalah bidang halaman yang dibatasi pagar keliling dan di dalam halaman tersebut terdapat beberapa bangunan dengan tujuan tertentu (Munandar, 2005:XII). Sementara itu, puri dapat dibedakan menjadi tiga macam, Puri Dewa Agung, Puri Agung atau Puri Gede, dan Puri Saja atau Jero (Munandar, 2005:4).

Dalam kaitan antara pariwisata dan budaya di Bali, Pitana (2000:5) berpandangan bahwa pariwisata merupakan sebuah tantangan atau juga ancaman dan di saat yang sama di sana terdapat peluang bagi masyarakat Bali untuk menemukan atau bahkan kehilangan identitas, agama, seni dan berbagai tradisi. Dengan kata lain, pariwisata mempunyai dua sisi di mana dalam budaya Bali disebut dengan rwabhineda.

Pitana (2000:33) mencatat bahwa pariwisata telah membuka kesempatan kerja bagi masyarakat, baik secara langsung maupun tidak langsung. Sebagai contoh, pengembangan pariwisata pada 
heritage sites dapat meningkatkan penghasilan dan taraf hidup masyarakat lokal. Hal tersebut dapat merangsang perekonomian di daerah pedesaan dan wilayah terpencil dengan menciptakan permintaan pada produk pertanian, dan melalui pembangunan infrastruktur (Timothy dan Nyaupane, 2009:33; Comer, 2012:3). Selain itu, Engelhardt (2005) dalam Timothy dan Nyaupane (2009:34) menambahkan bahwa heritage tourism juga dapat membantu memberdayakan masyarakat lokal.

Lee et al. (2007:1) berpendapat bahwa, merawat cultural heritage assets adalah penting, karena lewat kegiatan itu masyarakat tak hanya akan menumbuhkan rasa memiliki tanggung jawab terhadap terhadap warisan budaya yang ada tetapi juga bertanggung jawab kepada generasi mendatang. Generasi depan memiliki hak untuk mewarisi cultural heritage.

Faktanya adalah puri yang berdiri di Pulau Bali kini semakin sedikit, hal tersebut dikarenakan sebagian puri itu telah rusak dan tidak diperbaiki, dan hanya sebagian lagi yang masih terawat dengan baik (Munandar, 2005:1). Para ahli menyebutkan bahwa, salah satu masalah yang sangat menonjol dan mendesak di negara berkembang adalah penjarahan dan penggalian ilegal (Timothy dan Nyaupane, 2009:23). Selain itu, untuk negaranegara berkembang, di mana sebagian besar penduduknya sedang berusaha untuk memenuhi kebutuhan primer, pelestarian budaya sering kali tidak mendapatkan prioritas utama (Timothy dan Nyaupane, 2009:35).

Salah satu puri di Bali yang perlu diperhatikan perkembangannya adalah Puri Gede Karangasem karena puri ini saat ini sudah tidak lengkap lagi. Banyak bangunan yang telah hancur dan diganti dengan bangunan baru. Begitupun pelebahan-pelebahan puri sudah tidak utuh, tembok keliling atau tembok pembatasnya sudah banyak yang roboh (Munandar, 2005:64).

Fenomena tersebut menimbulkan pertanyaan, bagaimana heritage yang ada pada saat ini dapat dimanfaatkan sedemikian rupa sehingga masih dapat dinikmati untuk generasi mendatang (Timothy dan Nyaupane, 2009:250). Meskipun, secara optimis 
McKean (dalam Pitana 2000:39) menyatakan bahwa pariwisata tidak akan menghancurkan kebudayaan Bali, maka sebaliknya akan menguatkan budaya itu sendiri. Chang (1997:46) menambahkan bahwa, kesan komodifikasi heritage mengarah kepada inauthenticity perlu dievaluasi kembali.

Mengingat heritage site sebagai salah satu bentuk atraksi wisata adalah komponen paling penting dalam sistem kepariwisataan, serta juga merupakan motivator utama dalam melakukan perjalanan wisata dan merupakan bagian inti dari produk pariwisata. Maka, tanpa atraksi tidak akan ada kebutuhan untuk jasa pariwisata lainnya. Dengan kata lain pariwisata akan dapat bertahan dengan adanya atraksi wisata sebagai satu kesatuan dengan komponen lainnya (Swarbrooke, 2002:3). Oleh karena itu, pengelolaan yang tepat terhadap suatu atraksi wisata khususnya heritage site sangat diperlukan guna menjaga keberlanjutan suatu produk wisata.

\section{Tri Hita Karana dan Pariwisata Berkelanjutan}

SalahsatukearifanlokalmasyarakatBaliyangdimanfaatkan sebagai konsep pengembangan pariwisata berkelanjutan adalah Tri Hita Karana (THK). Bagi masyarakat Hindu-Bali, konsep THK telah menjadi panduan dalam kegiatan dan kehidupannya sehari-hari. Dimana dalam pelaksanaannya THK tidak hanya merupakan suatu filosofi agama, tapi merupakan suatu konsep yang mengandung nilai-nilai universal (Suteja, 2012:24; Dalem, 2007:83).

Dalam perkembangannya, unsur-unsur THK mengalami modifikasi menjadi parahyangan, palemahan dan pawongan. Dimana pada dasarnya THK berarti tiga sumber kebahagiaan atau kesejahteraan, yaitu hubungan yang harmonis dan seimbang antara manusia dengan Tuhan (aspek spiritual/parahyangan), antara manusia dengan manusia lainnya (aspek masyarakat/ pawongan), dan antara manusia dengan lingkungan (aspek lingkungan/palemahan) (Dalem, 2011:5; Marjaya, 2010:1; Suteja, 2012:15). 
Karena itu, kajian tentang implementasi konsep THK pada atraksi wisata budaya, khususnya pada cultural heritage di Puri Karangasem perlu dilakukan agar dapat dijadikan referensi bagi pengelolaan atraksi atau elemen pariwisata yang lain. Kajian tersebut juga akan membantu mengetahui bagaimana konsep THK sebagai salah satu kearifan lokal, dapat diaplikasikan pada sistem pariwisata. Sehingga dapat menjabarkan tatanan ideal/ konseptual (filsafat) ke dalam tataran instrumental, dimana salah satunya pada aspek atraksi wisata (Dalem, 2007:83).

Hal tersebut juga sejalan dengan tujuan dibentuknya konsep tersebut, bahwa penelaahan nilai-nilai universal THK secara ilmiah berdasarkan rasio dan logika umum, sebaiknya dipertajam dan dikembangkan lagi (Suteja, 2012:25), termasuk dalam bidang pariwisata.

\section{Fokus Kajian dan Data}

Penelitian ini dilakukan di Puri Agung Karangasem yang terletak di pusat Kota Amlapura (ibukota kabupaten), Kabupaten Karangasem, Provinsi Bali pada bulan Juni sampai dengan September 2013. Penelitian ini difokuskan untuk memahami gejala kepariwisataan yang terkait dengan implementasi konsep THK pada cultural heritage attraction dengan tujuan (1) mengidentifikasi potensi Puri Agung Karangasem sebagai produk wisata budaya, (2) mengidentifikasi motivasi wisatawan mengunjungi Puri Agung Karangasem dan mengkaji perbedaannya antara wisatawan "western" dan "eastern", (3) mengidentifikasi jenis wisatawan yang mengunjungi Puri Agung Karangasem, (4) mengkaji penerapan konsep THK sebagai konsep pengelolaan cultural heritage tourist attraction di Puri Agung Karangasem, (5) mengidentifikasi dampak dari penerapan konsep THK terhadap keberlanjutan kegiatan pariwisata di Puri Agung Karangasem.

Adapun data yang digunakan di antaranya; data primer yang diperoleh dari (1) kuesioner, dimana memiliki informasi tentang demografi, travel behaviour dan motivasi responden, yang terdiri atas 50 wisatawan mancanegara dan 50 wisatawan 
domestik, (2) semi-structural interview, dimana infroman berasal dari pengelola Puri Agung Karangasem, masyarakat lokal dan para ahli. Informan akan mengemukakan opini, ide, persepsi dan pengalaman mereka terkait dengan THK, pariwisata berkelanjutan dan pengelolaan Puri Agung Karangasem, (3) check-list, dimana peneliti melakukan observasi terkait dengan potensi wisata di Puri Agung Karangasem. Sedangkan data sekunder di dapat melalui dokumen-dokumen yang terkait dengan penelitian tersebut.

Selanjutnya metode yang digunakan adalah pendekatan "multi-method" (Jonker and Pennink, 2010:92). Dimana metode tersebut mengkombinasikan antara kualitatif dan kuantitatif yang disajikan secara deskriptif.

\section{Potensi Puri Agung Karangasem sebagai cultural tourism product}

Hubungan antara heritage dan pariwisata adalah suatu bidang yang strategis dalam mengkaji heritage tourism. Ballesteros et al. (2008:121) mencatat bahwa hubungan antara heritage dan pariwisata tidak hanya tentang bagaimana heritage mendukung pariwisata, akan tetapi juga sebaliknya bahwa pariwisata mendukung heritage dalam usaha keberlanjutan. Hal tersebut dikarenakan warisan budaya baik besar maupun kecil masingmasing memiliki nilai informasi tentang masa pembuatannya, teknologi, fungsi, keindahan, dan pandangan atau alam pikiran individu dan/atau masyarakat pembuatnya, informasi tersebut dapat menjadi daya tarik bagi masyarakat atau wisatawan (Ardika, 2007:10). Selain itu Chang (1997:47) mencatat bahwa mengubah kebudayaan lokal dan gaya hidup sebagai komoditi yang dijual untuk orang asing merupakan fenomena pariwisata heritage.

Prentice (1993:5) berpendapat bahwa berdasarkan sudut pandang pariwisata, makna suatu heritage tidak hanya sekedar bentang alam, bangunan bersejarah dan tradisi budaya, akan tetapi juga merupakan satu kesatuan dari berbagai elemen yang dapat digunakan sebagai sarana promosi bagi suatu produk wisata. Cooper et al. (1996:80-81) secara lebih dalam menjelaskan bahwa 
tourism product merupakan suatu kombinasi antara berbagai atraksi yang didukung oleh berbagai support facilities. Istilah yang biasa digunakan adalah four $A^{\prime}$ 's, dimana dapat dijabarkan menjadi attraction, accessibilities, amenities dan ancillary. Namun, dalam perkembangannya, Madiun (2012:3) menambahkan bahwa community involvement merupakan bagian penting dari perkembangan tourism product, khususnya dalam menjawab isu pariwisata berkelanjutan. Berdasarkan pemahaman tersebut, maka potensi Puri Agung Karangasem sebagai suatu atraksi wisata dapat diidentifikasi berdasarkan faktor-faktor tersebut.

Tabel 1

10 Destinasi di Karangasem yang Banyak Dikunjungi

Wisatawan tahun 2013

\begin{tabular}{|c|l|c|c|c|}
\hline Peringkat & \multicolumn{1}{|c|}{$\begin{array}{c}\text { Atraksi di } \\
\text { Kabupaten } \\
\text { Karangasem }\end{array}$} & $\begin{array}{c}\text { Wisatawan } \\
\text { Domestik }\end{array}$ & $\begin{array}{c}\text { Wisatawan } \\
\text { Inter- } \\
\text { nasional }\end{array}$ & Total \\
\hline $\mathbf{1}$ & Taman Ujung & 84,368 & 24,853 & 109,221 \\
\hline $\mathbf{2}$ & Besakih & 14,587 & 86,626 & 101,213 \\
\hline $\mathbf{3}$ & Tulamben & 21,811 & 51,324 & 73,135 \\
\hline $\mathbf{4}$ & Tirta Gangga & 18,629 & 49,511 & 68,140 \\
\hline $\mathbf{5}$ & Tenganan & 15,832 & 33,079 & 48,911 \\
\hline $\mathbf{6}$ & Telaga Waja & 3,476 & 28,608 & 32,084 \\
\hline $\mathbf{7}$ & Jemeluk & - & 9,920 & 9,920 \\
\hline $\mathbf{8}$ & Puri Agung & 362 & 8,780 & 9,142 \\
\hline $\mathbf{9}$ & Karangasem & & & 7,317 \\
\hline $\mathbf{1 0}$ & Cadang Bai & 316 & 7,001 & 1,667 \\
\hline
\end{tabular}

Sumber: Badan Pusat Statistik (bps.go.id)

Data di atas menunjukan bahwa Puri Agung Karangasem memiliki peluang untuk meningkatkan jumlah kunjungan, dengan memanfaatkan berbagai jenis atraksi wisata disekitarnya sebagai atraksi penunjang. Keberadaan atraksi tersebut dapat 
mendukung potensi yang dimiliki oleh Puri.

Hasil penelitian ini menunjukan bahwa Puri Agung Karangasem memiliki potensi sebagai produk wisata budaya. Hal ini dapat dilihat dari beberapa faktor, Pertama dari faktor atraksi. Puri Agung Karangasem memiliki daya tarik utama berupa bangunan bersejarah, arsitektur, pemandangan alam dan bentang alam, desa budaya dan historic people (keluarga keturunan kerajaan).

\section{Foto 1}

\section{Puri Agung Karangasem}

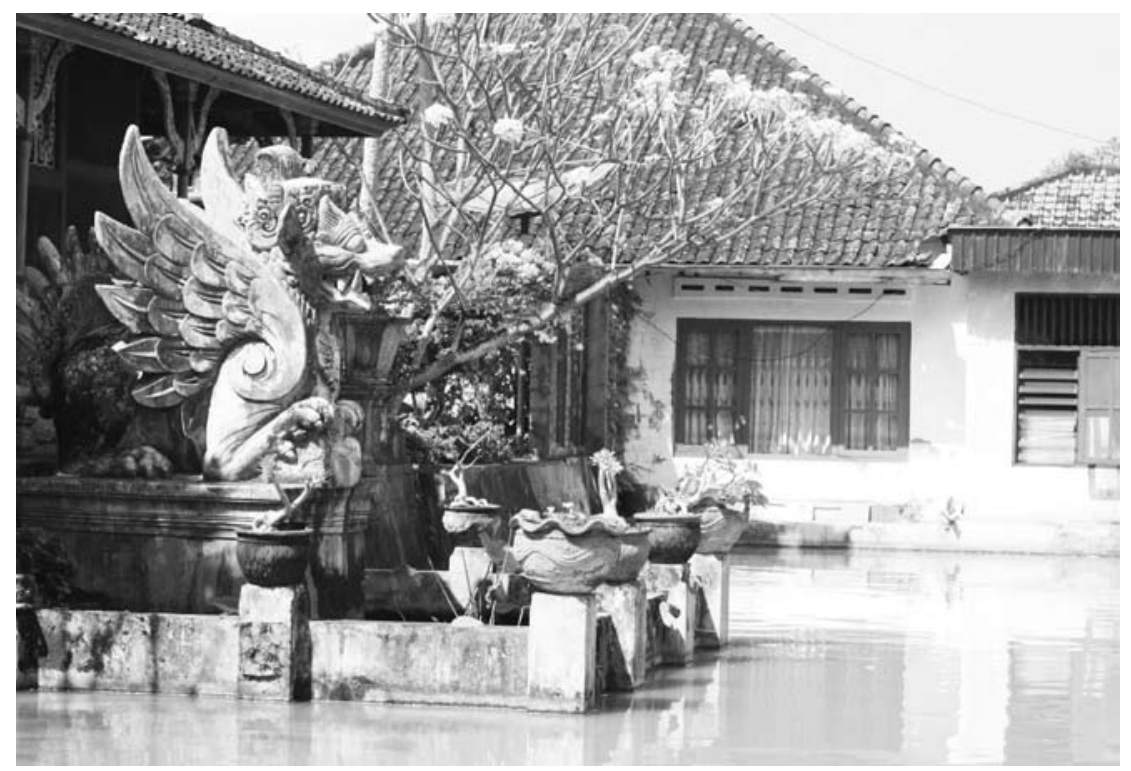

Sumber: Observasi oleh Kadek Wiweka

Berdasarkan hasil survei, data menunjukan daya tarik tersebut dianggap sebagai faktor yang penting, baik oleh wisatawan domestik maupun mancanegara. Namun, terdapat perbedaan dalam hal motivasi, dimana wisatawan mancanegara lebih memiliki "enthusiasm" terhadap heritage attraction. Sebagai contoh, wisatawan mancanegara memiliki motivasi utama untuk mencari "values" dari heritage site seperti : menambah wawasan 
dan meningkatkan pengetahuan, sedangkan wisatawan domestik memiliki motivasi utama untuk memanfaatkan waktu luang dan keluar dari rutinitas.

Selain itu Puri Agung Karangasem juga memiliki potensi yang dapat dikembangkan sebagai atraksi utama seperti seni tradisional, keragaman etnik dan festival atau events. Faktorfaktor tersebut dinilai belum menjadi faktor penting sebagai suatu atraksi wisata. Pemanfaatan faktor tersebut telah terbukti dapat meningkatkan jumlah kunjungan ke heritage site.

Kedua, dari faktor accessibility dapat dibedakan menjadi dua; yaitu dari aspek fisik dan informasi. Dari aspek fisik, akses yang ada di Kabupaten Karangasem mampu mendukung kegiatan pariwisata di Puri Agung Karangasem dan atraksi wisata lainnya. Jalan umum dengan kondisi yang cukup baik tersebar di dalam kabupaten atau bahkan yang menghubungkan ke pusat kota seperti Denpasar. Selain itu, keberadaan pelabuhan Padang Bai juga dapat mengakomodasi kapal-kapal dengan tujuan bisnis maupun pariwisata.

Sedangkan dari aspek akses informasi, strategi promosi yang digunakan oleh manajemen Puri Agung Karangasem cukup efektif. Survey menunjukan bahwa travel agent dan internet merupakan media informasi yang paling banyak digunakan baik oleh wisatawan domestik maupun internasional. Hal ini dapat disebabkan oleh sebagian besar responden dikategorikan sebagai "young tourist" dan memiliki latar belakang pendidikan tinggi.

Ketiga, dari aspek amenities di Puri Agung Karangasem, data menunjukan bahwa berbagai jenis fasilitas wisata telah mendukung kegiatan pariwisata. Fasilitas tersebut seperti akomodasi, restoran, rumah sakit, klinik, SPA, toko souvenir dan berbagai fasilitas relaksasi. Fasilitas tersebut tersebar di sekitar Kabupaten Karangasem seperti Tulamben, Amed dan Padang Bay. Sebagai akibatnya, survey menunjukan bahwa akomodasi dan toko cinderamata merupakan faktor yang kurang penting (kelemahan) bagi wisatawan.

Keempat, aspek ancillaries. Dalam hal manajemen, 
meskipun pemerintah lokal telah terlibat sebagai pengawas, namun perannya kurang maksimal. Minimnya sosialisasi tentang bagaimana mengelola heritage site belum berjalan dengan baik. Sebagai contoh, pengelolaan benda bersejarah dan kebersihan masih terlihat tradisional.

Kelima, aspek community involvement. Pemberdayaan masyarakat di lingkungan Puri Agung Karangasem telah diimplementasikan dengan baik. Selain dari komposisi pekerja, di mana $100 \%$ merupakan masyarakat lokal yang terdiri atas ticketing staff dan tiga orang pengelola lingkungan Puri. Masyarakat lokal juga terlibat secara aktif dalam melindungi dan melestarikan seni dan budaya lokal, sebagai contoh masyarakat terlibat dalam kegiatan upacara, menjaga kebersihan lingkungan sekitar dan menjaga keamanan. Manajemen Puri juga memberikan kesempatan bagi masyarakat lokal untuk memanfaatkan ruang di lingkungan Puri sebagai sarana penunjang kegiatan seni dan budaya.

Berdasarkan fenomena tersebut, masyarakat lokal telah menerima benefits dari sektor pariwisata, baik dari segi ekonomi dan sosial budaya.

\section{Karakteristik socio-demographic Wisatawan di Puri Agung Karangasem}

"Tourist demand" atau permintaan wisatawan telah menjadi isu yang menarik dalam fenomena pariwisata, khususnya pada heritage tourism. Pemahaman yang baik tentang "background" dan kebutuhan wisatawan dapat membantu dalam menentukan strategi terkait dengan produk. Dalam era modern, sukses sebuah perencanaan wisata untuk menarik wisatawan sangat dipengaruhi oleh strategi mereka menganalisa target pasar.

Mathieson dan Wall (1982; dalam Cooper et al. 1996:15) berpendapat bahwa tourism demand dapat dilihat dari berbagai perspektif, salah satunya psikologis. Dari perspektif tersebut, wisatawan dapat dilihat berdasarkan motivasi dan kebiasaan (behaviour). 
Untuk mengidentifikasi faktor permintaan, penelitian ini menggunakan pendekatan socio-demographic yang terdiri dari informasi terkait usia, pendidikan, pendapatan, pekerjaan dan latar belakang socio-economic lainnya. Selain itu travel behaviour dan tourist's motivation juga menjadi fokus penelitian.

Hasil penelitian ini menunjukan bahwa sebagian besar responden yang mengunjungi Puri Agung Karangasem tergolong kaum muda (dalam usia produktif) dengan usia di antara 1850 tahun. Dari segi latar belakang pendidikan, baik wisatawan domestik dan mancanegara, memiliki latar belakang pendidikan yang diklasifikasikan kedalam "high level", di mana sebagian besar berlatar belakang bachelor, master dan more than 5 years university or college. Hanya $14 \%$ dengan latar belakang primary school dan high school.

Survei juga menunjukan sebagian besar (90\%) responden adalah pekerja (pekerja paruh waktu atau pekerja penuh) dan pelajar. Dari segi travel behavior, penelitian ini menunjukan beberapa hal yang menarik, di antaranya adalah; wisatawan mancanegara telah merencanakan liburan mereka 120 hari atau hampir 3 bulan sebelum melakukan perjalanan, sedangkan wisatawan domestik hanya memerlukan 6 hari atau hampir seminggu sebelum perjalanan. Hanya 16\% dari wisatawan domestik, yang seluruhnya tergolong wisatawan lokal (asli Bali) yang mengunjungi Puri Agung Karangasem.

Sebagianbesar(86\%)wisatawanmancanegarajugamemiliki length of stay lebih panjang (22 hari), sedangkan $22 \%$ wisatawan domestik (tidak termasuk wisatawan lokal atau asli Bali) berada di angka 7 hari. Hal ini juga mungkin disebabkan oleh jarak tempuh wisatawan mancanegara yang cukup jauh, sehingga memutuskan untuk tinggal lebih panjang. Baik wisatawan domestik maupun mancanegara memilih untuk melakukan perjalanan dalam skala kecil (bukan grup) dan menjadi "independent tourist". Survei menunjukan, hanya $2 \%$ wisatawan mancanegara yang memilih melakukan perjalanan dalam bentuk grup.

Berdasarkan sumber media informasi yang digunakan, 
ada beberapa hal yang menarik diantara kedua jenis responden. Jika wisatawan mancanegara lebih banyak menggunakan travel agent melalui brosur, majalah dan informasi dari internet. Wisatawan domestik masih terlihat menggunakan cara yang lebih "tradisional" seperti WOM (Word of Mouth), sedangkan hanya $28 \%$ yang memanfaatkan media brosur dan $16 \%$ media internet.

Kategori "young tourists" bagi wisatawan yang berkunjung ke Puri Agung Karangasem merupakan sebuah peluang dalam melakukan strategi pemasaran. Teknologi yang erat dengan generasi muda, mampu digunakan secara optimal untuk memperkenalkan produk dengan lebih atraktif.

Dalam hal motivasi, ada beberapa perbedaan antara wisatawan internasional dan domestik. Sebagai contoh wisatawan internasional lebih memiliki "enthusiasm" pada heritage attraction. Sebagai contoh, international tourists memiliki main motive untuk mencari «values» dari heritage site seperti menambah pengalaman dan pengetahuan. Wisatawan domestik memiliki main motive untuk memanfaatkan waktu luang dan keluar dari rutinitas.

\section{Dampak Implementasi THK terhadap Pariwisata Berkelanjutan}

Untuk mengkaji penerapan konsep THK sebagai konsep pengelolaan cultural heritage tourist attraction di Puri Agung Karangasem, penelitian ini menggunakan THK framework sebagai dasar merumuskan instrumen panduan wawancara dan kuesioner. Secara lebih spesifik, daftar pertanyaan dibuat mengacu pada masing-masing indikator pada tiap-tiap elemen (parahyangan, pawongan, dan palemahan).

Indikator tersebut digunakan sebagai landasan kriteria ideal dalam mengimplementasikan konsep THK di Puri Agung Karangasem. Informan yang terlibat adalah pengelola Puri Agung Karangasem, masyarakat lokal dan ahli yang terkait dengan THK atau pariwisata berkelanjutan.

Indikator yang dipakai dapat dijelaskan sebagai berikut: Pertama, elemen parahyangan (relegi/budaya): berasal dari kata hyang yang artinya Sang Hyang Widhi (Tuhan Yang Maha Esa) 
(Dalem, 2007:84). Lingkungan spiritual, merupakan aspek yang mengacu pada hubungan manusia dengan lingkungan spiritual yang menunjukan manusia sebagai homo religious atau sebagai ciptaan yang mempercayai adanya Tuhan (Suteja, 2012:29). Industri pariwisata diharapkan semaksimal mungkin menciptakan suasana religious baik di dalam maupun di luar lingkungan (Dalem, 2007:84).

Selanjutnya kriteria tersebut terdiri dari: (1) Keberadaan tempat-tempat suci (temple) baik sebelum atau sesudah perusahaan berdiri, (2) Penggunaan simbol-simbol keagamaan (Hindu), seperti patung, benda-benda suci, bendera, umbul-umbul, pelinggih dan lain-lain, (3) Melaksanakan upacara peringatan yang dilaksanankan oleh Agama Hindu, (4) Komunikasi atau hubungan dengan tempat suci yang ada di luar hotel/ perusahaan, (5) Perawatan dan pelestarian tempat-tempat suci, (6) Meningkatkan kualitas kebudayaan Bali dan ajaran agama Hindu, (7) Menggunakan konsep arsitektur tradisional Bali, (8) Mengatur dan menata tempat suci, (9) Pertunjukan kegiatan yang berkaitan dengan agama baik sehari-hari maupun berkala/periodik, (10) Berkontribusi dan berpartisipasi dalam kegiatan keagamanaa pada lingkungan sekitar (Suteja, 2012:28; Dalem, 2007:85).

Kedua, elemen pawongan (masyarakat): dimana kata wong yang berarti penduduk atau orang dalam masyarakat (Dalem, 2007:84). Lingkungan sosial, terdiri dari: (1) Suasana harmonis hubungan antara internal karyawan dan managemen, Adanya organisasi sosial kemasyarakatan dalam perusahaan, (3) Komposisi tenaga kerja lokal dalam perusahaan, (4)Meningkatkan potensi dari tenaga kerja lokal, (5) Suasana hubungan antara perusahaan dan masyarakat sekitar, (6) Mampu meningkatkan kemampuan ekonomi masyarakat sekitar, (7) Meningkatkan pengembangan sumber daya manusia di perusahaan, Meningkatkan kemampuan sumber daya manusia masyarakat sekitar (beasiswa, dan lain-lain), (9) Bersimpatik pada masalahmasalah kemanusiaan, (10) Berkontribusi dan berpartisipasi dalam menyelamatkan dan mengembangkan kebudayaan Bali 
(Suteja, 2012:28; Dalem, 2007:84).

Ketiga, elemen palemahan (lingkungan): dimana berasal dari kata lemah yang berarti tanah, tanah pekarangan atau wilayah pemukiman. Secara umum palemahan sebagai salah satu aspek THK merupakan segala sesuatu yang berhubungan dengan aspek fisik dari lingkungan. Hal ini dimaksudkan agar suatu perusahaan mampu menciptakan suatu sistem managemen lingkungan dan dapat menjabarkannya pada action plans hingga menerapkannya pada program-program. Pada aspek ini juga mengandung nilainilai universal seperti reusing, reducing dan recycling (Suteja, 2012:31-32; Dalem, 2007:87-88).

Indikatornya terdiri dari (1) Komitmen perusahaan terhadap kualitas lingkungan, (2) Penggunaan atau penerapan konsep dan style/ langgam arsitektur Bali, (3) Melestarikan dan mengembangkan ekosistem, (4) Mengelolaan material buangan atau limbah, seperti materi cair, padat dan gas, (5) Perusahaan berpartisipasi terhadap permasalahan lingkungan dalam lingkup lokal, nasional dan internasional, (6) Secara organisasi mengatur dalam pengelolaan lingkungan, (7) Memperhatikan penggunaan energi dan sumber daya alam, (8) Penamaan ruangan, bangunan, dan lain-lain sesuai atau harmoni dengan kebudayaan Bali, (9) Pengelolaan lingkungan berdasarkan pada hukum yang berlaku, (10) Memeriksa dan mengevaluasi pengelolaan lingkungan secara berkelanjutan (Suteja, 2012:28; Dalem, 2007:89-90).

Selanjutnya, berdasarkan indikator-indikator diatas, maka penelitian ini menemukan fakta implementasi THK di Puri Agung Karangasem sebagai berikut.

\subsection{Parahyangan}

Dalam hal parahyangan, Puri Agung Karangasem secara umum telah mampu membangun suasana religious baik di dalam, maupun di luar lingkungan Puri. Berbagai elemen religious seperti upacara keagamaan, arsitektur dan konsep bangunan dan sistem sosial telah dikombinasikan menjadi atraksi wisata. Meskipun semua elemen tersebut berjalan secara alami (tanpa 
perencanaan), akan tetapi keberadaannya sangat bermanfaat bagi kegiatan wisata di Puri Agung Karangasem.

Elemen ini menunjukan bahwa pariwisata dan budaya dapat dikembangkan secara bersama-sama dan membawa benefits satu sama lain. Tradisi dan kebiasaan masyarakat lokal di lingkungan Puri dan sekitarnya dapat menjadi daya tarik utama, sehingga dapat menarik wisatawan baik mancanegara maupun domestik. Di sisi lain, kegiatan pariwisata dapat membawa dampak ekonomi yang dapat digunakan untuk melindungi serta melestarikan budaya lokal.

\subsection{Pawongan}

Sementara, Puri Agung Karangasem telah mengimplementasikan dengan baik elemen pawongan (sosial/masyarakat). Hal tersebut dapat dilihat berdasarkan keterlibatan masyarakat terhadap kegiatan wisata di lingkungan Puri. Menciptakan lapangan pekerjaan baru bukan satu-satunya manfaat kegiatan wisata, khususnya dari sisi ekonomi. Akan tetapi secara lebih luas, Puri juga memberikan peluang bagi masyarakat lokal untuk memanfaatkan lingkungan Puri sebagai fasilitas pertunjukan seni dan budaya. Langkah tersebut dapat melindungi dan melestarikan kebudayaan lokal dengan cara melibatkan masyarakat lokal secara aktif, dalam hal ini keterlibatan masyarakat lokal juga dapat memberi dampak positif bagi elemen budaya (parahyangan).

Adapun beberapa kelemahan diantaranya adalah lemahnya pengembangan kualitas sumber daya manusia (SDM) di Puri Agung Karangasem, terutama dalam kaitan dengan wawasan pariwisata. Manajemen belum memiliki program yang nyata sebagai usaha meningkatkan kemampuan pekerja/karyawan yang terkait dengan pelayanan pariwisata. Hal tersebut menjadi isu penting sejak sebagian wisatawan telah focus terhadap kualitas pelayanan di Puri Agung Karangasem.

\subsection{Palemahan}

Elemen selanjutnya adalah palemahan (lingkungan). 
Meskipun hasil penelitian menunjukan bahwa lingkungan di Puri Agung Karangasem sudah memadai, akan tetapi, ada beberapa faktor yang masih dapat dikembangkan secara optimal, seperti pengembangan Standard Operating Procedure terkait dengan pengelolaan sumber daya heritage, hal ini termasuk benda-benda dan peninggalan bersejarah.

Penelitian menunjukan, sistem pengelolaan yang masih tergolong tradisional belum mampu melindungi dan memelihara lingkungan secara maksimal. Meskipun demikian, sistem tradisional Bali dalam menjaga lingkungan dipercaya dapat membawa dampak positif bagi elemen lain, seperti parahyangan dan pawongan.

Hal lain yang menjadi perhatian wisatawan, khususnya wisatawan mancanegara adalah faktor kebersihan. Berdasarkan survei faktor tersebut belum menjadi faktor yang penting sebagai bagian dari atraksi wisata di Puri Agung Karangasem.

\section{Simpulan}

Puri Agung Karangasem memiliki potensi sebagai produk wisata budaya. Hal tersebut dibagi menjadi dua bagian, dari sisi penawaran (supply) dan permintaan (demand). Dari sisi penawaran, Puri Agung Karangasem memiliki potensi attraction, accessibilities, amenities, ancillary dan community involvement. Seluruh komponen tersebut dikombinasikan menjadi sebuah produk wisata budaya yang dapat menjadi daya tarik bagi wisatawan.

Beberapa kelemahan seperti kurangnya pemanfaatan teknologi dalam mengelola dan memasarkan produk, packaging produk wisata (khususnya dalam hal seni dan budaya) dan terbatasnya wawasan serta keterampilan sumber daya manusia dalam hal pelayanan terkait dengan pariwisata. Beberapa faktor tersebut dapat menjadi peluang untuk meningkatkan jumlah kunjungan wisatawan, dengan catatan adanya program pengembangan pada seluruh faktor tersebut.

Dari sisi permintaan (demand), penelitian ini dapat menyimpulkan bahwa semua wisatawan yang berkunjung ke 
heritage attractions atau menikmati heritage sebagai "heritage tourists", tetapi dengan motivasi dan ketertarikan yang berbedabeda dapat diklasifikasikan ke dalam heritage tourists.

Sedangkan secara umum, impelementasi konsep THKyang dilakukan di Puri Agung Karangasem telah membawa dampak positif. Baik untuk kegiatan pariwisata yang berkelanjutan, maupun kelestarian seluruh potensi yang dimiliki oleh Puri Agung Karangasem. Hal ini membuktikan bahwa pariwisata dan budaya dapat dikembangkan secara bersama-sama dan saling mendukung satu sama lain.

Hal tersebut juga didukung oleh pernyataan salah satu informan sebagai ahli bidang pariwisata berkelanjutan, Raka Dalem, yang menyatakan bahwa peran THK sangatlah penting, mengingat sebagian besar sektor pariwisata belum konsisten mengaplikasikan konsep tersebut. Khususnya dalam menjaga keseimbangan seluruh elemen-elemen tersebut, sebagai contoh; di banyak kasus persoalan lingkungan belum mendapatkan perhatian yang besar dibandingkan masalah ekonomi. Atau bahkan, di beberapa kasus masyarakat lokal masih mendapatkan porsi yang kecil dalam hal keterlibatan langsung pada kegiatan pariwisata.

Konsistensi impelementasi nilai-nilai yang terkandung dalam konsep THK dapat mendukung tujuan pengembangan pariwisata berkelanjutan secara umum. Selain itu, secara khusus seluruh stakeholders dapat menikmati dampak positif kegiatan pariwisata dalam jangka panjang.

\section{Saran}

Penelitian ini menghasilkan beberapa rekomendasi, yang diantaranya adalah; rekomendasi terkait pada penggunaan teknologi. Puri Agung Karangasem diharapkan dapat memanfaatkan teknologi secara maksimal baik dalam mengelola potensi atau bahkan memperkenalkan produk mereka (marketing strategy). Salah satu media yang dapat digunakan adalah mobile application (software) dan multi-media technology (projector screen). 


\section{Foto 2}

Audio guide

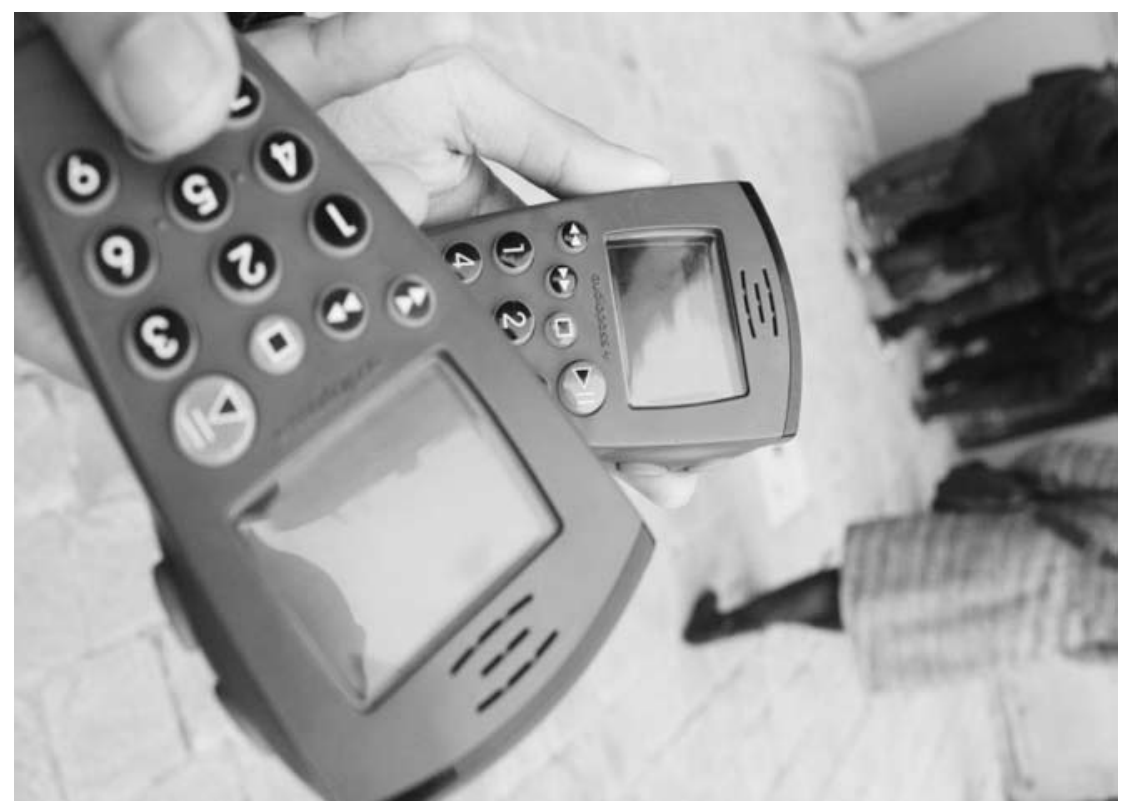

Sumber: Observasi oleh Kadek Wiweka (2014)

Dalam hal atraksi wisata, event dan festival di lingkungan Puri Agung Karangasen dapat dikemas lebih profesional menjadi atraksi wisata pendukung, dengan cara bekerja sama dengan travel agent lokal, pemerintah lokal, masyarakat lokal dan museum.

Pemanfaatan sebagian bagian di Puri Agung Karangasem sebagai tourist accommodation (dengan memperhatikan tata ruang dan fungsi bangunan, dikelola dengan profesional dan tidak dalam skala besar).

Mengembangkan standard operational dalam mengelola seluruh sumber daya dan meningkatkan kualitas. SOP dapat terdiri atas elemen-elemen praktis seperti services quality, kebersihan, safety dan security, pengelolaan dan konservasi (training and development program).

Penelitian terhadap Tri Hita Karana frameworks ini diharapkan dapat dikembangkan pada sektor lainnya seperti 
travel agent, restaurant dan atraksi wisata yang lain.

Kombinasi antara konsep internasional atau global dan kerifan lokal sangat diperlukan untuk memperkaya indikatorindikator Tri Hita Karana framework.

\section{UCAPAN TERIMA KASIH}

Penulis menyampaikan ucapan terima kasih kepada Madame Sylvine Chevalier Pickel sebagai penanggung jawab akademik program Double Degree Indonesia Prancis mahasiswa Universitas Udayana Bali di Université d'Angers, France. Prof. Dr. I Nyoman Sirtha, SH.,MS., sebagai mantan Ketua Program Studi Kajian Pariwisata Program Pascasarjana Universitas Udayana, dan Prof. Dr. I Nyoman Darma Putra sebagai Ketua Program Studi Kajian Pariwisata Program Pascasarjana Universitas Udayana saat ini. Apresiasi dan ucapan terima kasih juga penulis sampaikan kepada Bapak Nyoman Sunarta, M.Si sebagai Sekretaris Program Studi Kajian Pariwisata Program Pascasarjana Universitas Udayana terdahulu dan Dr. Ir. Syamsul Alam Paturusi, MSP sebagai Sekretaris Program Studi Kajian Pariwisata Program Pascasarjana Universitas Udayana saat ini. Prof. Dr. I Made Budiarsa, M.A dan Prof. Made Sudiana Mahendra, Mapp.Sc.Phd. sebagai dosen penguji yang telah memberikan banyak masukan, dan koreksi untuk menyempurnakan tesis ini.

UcapanterimakasihjugadidedikasikankepadaPemerintah Indonesia dan Prancis yang telah merancang Program Double Degree dan segala bentuk dukungan selama proses pendidikan, khususnya bagi mahasiswa yang berminat melanjutkan studi tentang pariwisata di dua Negara.

\section{BIOGRAFI PENULIS}

Kadek Wieka, S.ST.Par adalah alumnus Magister Kajian Pariwisata, Double Degree Indonesia Prancis, dengan menempuh 1 tahun pendidikan Master di Universitas Udayana Denpasar kemudian melanjutkan 1 tahun berikutnya di Université d'Angers, Prancis, jurusan Mention Management et Développement du Tourisme, de 
I'Hôtellerie, de la Restauration et des Loisirs. Ia menyelesaikan program studi Diploma IV, Manajemen Kepariwisataan di Sekolah Tinggi Pariwisata Nusa Dua Bali. Pengalaman yang dimiliki adalah pernah bekerja di Bali Internasional Airport Ngurah Rai, Berry Hotel Bali sebagai Front Office Staff dan tenaga pengajar di Fakultas Dharma Duta, Institut Hindu Dharma Negeri (IHDN) Denpasar sejak tahun 2011. Manajemen pariwisata adalah keahlian yang dimiliki dan digeluti sejak terlibat di bidang pariwisata.

\section{DAFTAR PUSTAKA}

Ardika, I Wayan. 2007. Pusaka Budaya dan Pariwisata. Denpasar: Pustaka Larasan.

Ballesteros et al. 2008. The Development of Mining Heritage Tourism: A Systemic Approach. In: TOURISM DEVELOPMENT: ECONOMICS, MANAGEMENT AND STRATEGY. Editor: ramos dan jiménez, New York: Nova Science Publishers.

Chang, T.C. 1997. "HERITAGE AS A TOURISM COMMODITY: TRAVERSING THE TOURIST-LOCAL DIVIDE" (Journal of Tropical Geography, Page 46-68). Singapore: Department of Geography, National University of Singapore, and Blackwell Publisher Ltd.

Comer, CDouglas. 2012. "Petra as a Bellwether Archeological Site on the World Heritage List". In: Tourism and Archaeological Heritage Management at Petra, Driver to Development or Destruction. Editor: Comer, C Douglas, USA: International Committee on Archeological Heritage Management (ICAHM).

Cooper, Chris et al. 1996. "TOURISM Principles \& Practice". Addison Wesley Longman Limited, Edinburg Gate, Harlow, Essex, CM20 2JE, England.

Dalem, A.A. G. R. 2007. Filosofi Tri Hita Karana dan Implementasinya Dalam Industri Pariwisata. Dalam: Kearifan Lokal Dalam Pengelolaan Lingkungan Hidup. Editor: Dalem, A. A. G. R et al., Denpasar: UPT Penerbit Universitas Udayana bekerjasama Pusat Pelatihan Lingkungan Hidup UNUD. 
Dalem, A. A. G. R. 2011. "Achievements and Challenges of Implementation of "Tri Hita Karana" for Creating Sustainable Tourism in Bali-Indonesia: A Case Study in Hotel Sectors". Journal of Ritsumeikan Social Sciences and Humanities (Japan) 3 (2011)

Jonker, Jan and Pennink, Bartjan. 2010."The Essence of Research Methodology, AConcise Guide for Master and PhD Student in Management Science". Springer-Verlag, Berlin, Heidelberg, Germany.

Lee et al. 2007. Introduction. In: Cultural Heritage Management in China: Preserving the cities of the Pearl River Delta. Editor Cros dan Lee, New York: Routledge - edition published in the Taylor and Francis e-Library.

Madiun, I Nyoman. 2012. The presentation of Global Tourism Geography Management: a basic concept. Universitas Udayana, Denpasar, Bali.

Marjaya, I Made. 2010. "Tri Hita Karana A Conception in Conducting Balinese Arts" (Paper).

Munandar, Agus. 2005. Istana Dewa Pulau Dewata: Makna Puri Bali Abad ke-14-19. Depok: Komunitas Bambu.

Peraturan Daerah Provinsi Bali Nomor 2 Tahun 2012 Tentang Kepariwisataan Budaya Bali.

Picard, Michel. 2006. "Bali Pariwisata Budaya dan Budaya Pariwisata". Jakarta: Kepustakaan Populer Gramedia.

Pitana, I. Gede. 2000. "Cultural Tourism in Bali: A Critical Appreciation". Denpasar: Research Center for Culture and Tourism, University of Udayana.

Prentice, Richard. 1993. Tourism and Heritage Attractions. 11 New Fetter Lane, London EC4P 4EE: Routledge.

Suteja, Mertha. 2012. Tri Hita Karana and World Peace, Bali Hinduism Philosophy of Life. Surabaya: Paramita.

Swarbrooke, John. 2002. The Development and Management of Visitor Attractions. Oxford: Butterworth-Heinemann, Reed Educational and Professional Publishing. 
Kadek Wiweka

Timothy and Nyaupane. 2009. Cultural Heritage and Tourism in the Developing World: A regional perspective. New York: Routledge edition published in the Taylor and Francis e-Library.

\section{Website:}

The Statistic of Top 10 Visit to Place of Interest in Bali. 2008-2012. Bali Government Tourism Office. In http://www.disparda.baliprov. go.id/informasi/2010/12/statistics. Accessed on 12 November 2013.

160 JUMPA Volume 01, Nomor 01, Juli 2014 